\title{
K wie Kongress oder es muss nicht immer Hochglanz sein
}

\section{Dominik Heim}

PD Dr. med., Facharzt für Chirurgie, Mitglied FMH

Man kann in der hintersten oder in der vordersten Reihe bei den Referenten sitzen oder man wechselt von backstage zu frontstage und hofft, dass alles klappen wird, Kongresse haben für jeden etwas. Man geht, um etwas zu lernen, um zu diskutieren, und auch - um die Credits abzuholen. Ein paar Unverdrossene organisieren diese Kongresse auch und schreiben dann einander im Sinne einer Zwischenbilanz: «Aktuell habe ich grad ein bisschen die Schattenseiten der Kongressorganisation kennengelernt (Sponsoringrückgang, Kosten der organisierenden Firmen ...), aber das Wissenschaftliche macht Spass.» Wie wahr!

Es gab eine Zeit, da war die Symbiose von Medizin und Industrie eine Glückliche. Man lebte in der vielbeschworenen Win-win-Situation. Die Pausen mussten eine gewisse Länge haben, damit diese Symbiose auch zum Tragen kam. Wo sind heute all diese Industrie-Stände? Ihre Lücke hinterlässt Spuren in der Schlussabrechnung. 2012 hatte ich das Privileg, einen grossen europäischen Trauma- und Notfallchirurgie-Kongress in Basel zu organisieren. Es kamen rund 1200 delegates, und die Angst vor einem finanziellen Einbruch war dank den Onsite-Registrationen schlussendlich unbegründet. Es gab viel Kultur: Eliana Burki kam, Max Lässer und sein Überlandorchester waren da, George Gruntz gab eines seiner letzten Konzerte ... Dank grosszügiger Unterstützung von vielen Organisationen war das alles möglich. Seither schreibt diese Gesellschaft an jedem Kongress rote Zahlen. Die grossen Ausstellungshallen der Kongresskathedralen sind nicht mehr gefüllt. Haben kann man zwar auch heute noch (fast) alles, aber ein 4. Headphone und ein zusätzlicher Scheinwerfer kosten separat. Auch die professionelle Kongressorganisation (PCO), die uns laien-kongressorganisierende Mediziner mit ihrer Routine unterstützt, kostet. Und auch da hört man dann: «Leider sind diese Arbeiten im Leistungsumfang nicht vereinbart worden und unsere Organisation muss diese Mehraufwände zusätzlich in Rechnung stellen.» Alles hat seinen Preis. Ja, da denkt man dann an all die Stunden, die man in enthusiastischer «Fronarbeit" mit der neuen CD von Eric Clapton (heisst sinnigerweise I still do, ja, genau, ich auch) im Ohr am Abend und am Wochenende verbracht hat. Und wenn Fred Chapellier (der französische Blueser, der auch schon

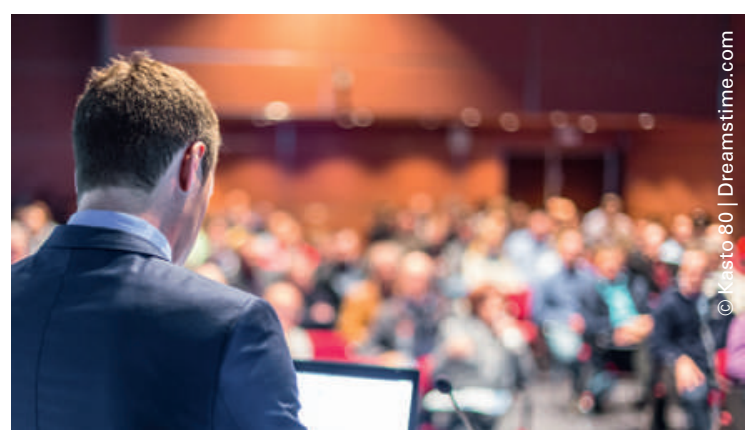

mit Jacques Dutronc unterwegs war) sagt «it never comes easy", muss man zustimmend nicken.

Die heutige medizinische Kongresskultur erinnert an die Immobilienblase, die plötzlich platzen könnte. An den industriellen Rahmenbedingungen wird sich wohl nicht viel ändern lassen. Da, wo's für den Absatz etwas zu holen gibt, da ziehen sie hin (ich kenne Ausnahmen!). An den anderen Bedingungen sind aber Änderungen möglich. Braucht es immer einen Kongress-Tempel, braucht es immer einen PCO? Es gibt da eine (andere) europäische Gesellschaft, die in ihren Richtlinien eine professionelle Kongressorganisation sogar verbietet. Und sie kommt 2019 in die Schweiz. Auch der location gebührt Aufmerksamkeit, der Aufwand muss sinken. Es gibt ja neben den Hollywood-Blockbustern auch Low-Budget-Filme, die so vieles zu sagen haben, dass man auf dem Heimweg mit dem Velo in der Nacht fast das Rotlicht überfährt, auch wenn es nicht Batman und Superman gewesen sind, die sich da soeben auf der Leinwand getroffen haben ...

Nein, es muss nicht immer Hochglanz sein, vielleicht tut's eine schlichtere Form auch. Es geht in der Sache immer noch um die Medizin, es braucht keine deluxe edition zu sein. Joe Bonamassa's Blues of Desperation würde auch ohne deluxe phantastisch dröhnen. Aber es braucht persönliches Engagement und viel Phantasie, um einen Kongress «auf die Bühne zu bringen» - und nicht auf die Kultur verzichten zu müssen! «Keep it simple», sagte der bekannte englische Orthopäde A.G. Apley (1914-1996). Und wie zur Erklärung sagte er dann vor vielen Jahren an einem AO-Kurs in Davos auch: "Fracture healing is like sex, it's natural, needs two parts ... and a bit of movement.» Eigentlich simple! 